\title{
Geomedical studies on fluorosis in dairy animals in Punjab, India
}

\author{
SP Sharma, SS Randhawa, RS Brar \\ COVSC, Punjab Agricultural University, Ludhiana 141004, India
}

Fluorosis is a world wide problem affecting human beings as well as livestock. Toxic levels of fluoride (over $1 \mathrm{ppm}$ ) in water have been detected in many parts of Punjab State in India. The present investigation was undertaken to study the symptomatology and haemato-biochemical alterations in fluorotic dairy animals.

Clinical cases of fluorosis in 39 adult buffaloes, confirmed on the basis of drinking ground water and plasma fluoride contents, were included for haemato-biochemical studies. Blood samples from 10 healthy buffaloes were also analysed for establishing control values. The $\mathrm{Hb}$ was estimated by the cyanomethaemoglobin method whereas PCV and TEC were determined by using haematocrit tubes and haemocytometer, respectively. Plasma ALT (alanine aminotransferase), AST (aspartate aminotransferase) ALP (alkaline phosphatase), urea nitrogen (UN) and creatinine were estimated by using reagent kits with the help of Beckman Clinical Analyser (USA). Plasma and water $F$ content was estimated by fluoride ionic specific electrode. Plasma minerals were analysed on inductably coupled argon plasma atomic emission spectrophotometer.

Adult buffaloes were much more affected than cows. Incidence was significantly higher during summer season. Chief clinical signs of fluorotic animals were mottling, excessive wear and pitting of teeth, lowered milk yield, emaciation, lameness and exostoses of long bones. Haemogram of fluorotic animals revealed anaemia reflected by significant $(P \leq 0.05)$ decline in mean $\mathrm{Hb}(9.10 \mathrm{~g} / \mathrm{dl})$, PCV $(29 \%)$ and TEC $\left(6.69 \times 10^{6} / \mathrm{mm}^{3}\right)$ as compared to respective mean values of $12.2 \mathrm{~g} / \mathrm{dl}, 36.6 \%$ and $8.60 \times 10 \% / \mathrm{mm}^{3}$ in healthy controls. Mean plasma UN and creatinine in affected buffaloes was significantly $(P \leq 0.05)$ increased to 25.4 and $1.89 \mathrm{mg} / \mathrm{dl}$, respectively as compared to respective mean values of 14.6 and $1.50 \mathrm{mg} / \mathrm{dl}$ in healthy controls, reflecting muscular and especially renal damage. Plasma enzymes ALT, AST and ALP were significantly increased in fluorotic animals indicating degenerative changes especially involving liver and bones. The plasma minerals revealed significant $(P \leq 0.05)$ increase in $F(0.38 \mathrm{ppm})$ as compared to mean $F$ content of $0.11 \mathrm{ppm}$ in healthy controls. This was associated with decline in plasma $\mathrm{Ca}, \mathrm{P}, \mathrm{Cu}$ and $\mathrm{Mn}$ in affected animals. The $F$ content of drinking water in fluorotic areas ranged from over $1-9 \mathrm{ppm}$ as compared to $0.4-0.8 \mathrm{ppm} F$ in non-fluorotic areas.

It was inferred that prolonged exposure of animals to toxic levels of $F(>1 \mathrm{ppm})$ in drinking water (hydrofluorosis) resulted in anaemia, hepatic, kidney and bone disorders associated with significant alterations in plasma mineral status. 